Pacific Journal of Mathematic

Mormaxrme sixteen 


\section{DIOPHANTINE SYSTEMS}

\section{A. A. AUCOIN}

We concern ourselves in this paper with integral solutions of three Diophantine systems, generalizations of

$$
x+y+z=u+v+w, x y z=u v w
$$

and of $x y+x z+y z=u v+u w+v w, x y z=u v w$. The solutions are given in terms of parameters and are integral for an integral choice of the parameters. Throughout the paper the integer $n$ will be greater than 1 .

Heron [3] in the first century B. C. considered the problem of finding two rectangles such that the area of the first is three times the area of the second and the perimeter of the second is three times of perimeter of the first. He also considered a second problem which results in the Diophantine system $x+y=u+v, x y=4 u v$. Planude [3] discussed the system $x+y=u+v, x y=b u v$, and Cantor [3] gave general solutions to this problem. Tannery [3] generalized the two problems of Heron. Moessner [7] and [8] gave particular solutions, while Dickson [4] and Gloden [6] gave parametric solutions of the system

$$
\begin{aligned}
x+y+z & =u+v+w \\
x y z & =u v w
\end{aligned}
$$

Bini [1] considered a system equivalent to (1) and Buquet [2] extended this system to $2 n$ unknowns.

All of the above systems are special cases of the system

$$
\begin{aligned}
A(x, y) & =0, \\
c P(x) & =d P(y),
\end{aligned}
$$

where $A(\alpha, \beta)=\sum_{i=1}^{n}\left(a_{i} \alpha_{i}-b_{i} \beta_{i}\right), P(\alpha)=\prod_{i=1}^{n} \alpha_{i}, a_{i}, b_{i}$ are integers, and $c$ and $d$ are nonzero integers. We make the following definitions:

$$
A_{p}(\alpha, \beta)=A(\alpha, \beta)-\left(a_{p} \alpha_{p}-b_{p} \beta_{p}\right) \text {, }
$$

$P_{p}(\alpha)=P(\alpha) / \alpha_{p}, \pi_{1}(\alpha, \beta)=c b_{p} P_{p}(\alpha)-d a_{p} P_{p}(\beta), p$ is a fixed integer, $1 \leqq p \leqq n$, and the $\alpha$ 's and $\beta$ 's are arbitrary integers.

We agree that solutions in which some unknown vanishes, or those for which $a_{i} x_{i}=b_{i} y_{i},(i=1, \cdots, n)$ are trivial solutions.

THEOREM. 1. Any nontrivial integral solution of (2) is proportional to a solution given by 


$$
\begin{aligned}
& x_{i}=\pi_{1}(\alpha, \beta) \alpha_{i}, \quad i \neq p, \\
& y_{i}=\pi_{1}(\alpha, \beta) \beta_{i}, \quad i \neq p, \\
& x_{p}=d P_{p}(\beta) A_{p}(\alpha, \beta), \\
& y_{p}=c P_{p}(\alpha) A_{p}(\alpha, \beta) .
\end{aligned}
$$

Proof. Since the solution is nontrivial there is an integer $p$, $1 \leqq p \leqq n$, such that $a_{p} x_{p} \neq b_{p} y_{p}$. If for $i \neq p$ we set

$$
\begin{aligned}
& x_{i}=\pi_{1}(\alpha, \beta) \alpha_{i}, \\
& y_{i}=\pi_{1}(\alpha, \beta) \beta_{i},
\end{aligned}
$$

then (2) becomes

$$
\begin{gathered}
a_{p} x_{p}-b_{p} y_{p}=-\pi_{1}(\alpha, \beta) A_{p}(\alpha, \beta), \\
c P_{p}(\alpha) \pi_{1}^{n-1}(\alpha, \beta) x_{p}-d P_{p}(\beta) \pi_{1}^{n-1}(\alpha, \beta) y_{p}=0 .
\end{gathered}
$$

The solution of this system is

$$
\begin{aligned}
& x_{p}=d P_{p}(\beta) A_{p}(\alpha, \beta), \\
& y_{p}=c P_{p}(\alpha) A_{p}(\alpha, \beta) .
\end{aligned}
$$

From (4) and (5) it follows that (3) is a solution of (2).

Suppose now that $x_{i}=\lambda_{i}, y_{i}=\mu_{i}$ is a non trivial integral solution of (2). Then $A(\lambda, \mu)=0, c P(\lambda)=d P(\mu)$, and $a_{p} \lambda_{p} \neq b_{p} \mu_{p}$. If in (3) we choose $\alpha_{i}=\lambda_{i}, \beta_{i}=\mu_{i}$ we get

$$
\begin{aligned}
& x_{i}=\pi_{1}(\lambda, \mu) \lambda_{i}, \quad(i=1, \cdots, n), \\
& y_{i}=\pi_{1}(\lambda, \mu) \mu_{i}, \quad(i=1, \cdots, n) \text {, }
\end{aligned}
$$

which is proportional to the solution $x_{i}=\lambda_{i}, y_{i}=\mu_{i}$, since $\pi_{1}(\lambda, \mu)$ is integral and $\pi_{1}(\lambda, \mu)=c P(\lambda) / \lambda_{p} \mu_{p}\left(b_{p} \mu_{p}-a_{p} \lambda_{p}\right) \neq 0$.

Dickson [5] has given solutions of the system

$$
\begin{aligned}
x y+x z+y z & =u v+u w+v w, \\
x y z & =u v w .
\end{aligned}
$$

$\mathrm{He}$ [4] also indicates that this system may be solved by the same method he used to solve (1). Our second theorem generalizes (6).

We wish to solve the system

$$
\begin{aligned}
\sum_{i=1}^{n}\left[\frac{a_{i} P(x)}{x_{i}}-\frac{b_{i} P(y)}{y_{i}}\right] & =0, \\
c P(x) & =d P(y),
\end{aligned}
$$

where $a_{i}, b_{i}, c, d, P(\alpha), P_{p}(\alpha)$ are the same as in Theorem 1 . We set

$$
P_{p i}(\alpha)=\frac{P(\alpha)}{\alpha_{p} \alpha_{i}}, B(x)=\sum_{i=1}^{n}{ }^{\prime} a_{i} P_{p i}(x), C(y)=\sum_{i=1}^{n}{ }^{\prime} b_{i} P_{p i}(y),
$$


where $\Sigma^{\prime}$ indicates that the $p^{\text {th }}$ term is omitted from the summations, $\pi_{2}(\alpha, \beta)=c P_{p}(\alpha) C(\beta)-d P_{p}(\beta) B(\alpha), p$ is a fixed integer, $1 \leqq p \leqq n$, and the $\alpha$ 's and $\beta$ 's are arbitrary integers.

We agree that solutions in which some unknown vanishes or any solution for which $a_{i} P(x) / x_{i}=b_{i} P(y) / y_{i},(i=1, \cdots, n)$, are trivial solutions.

THEOREM ${ }^{1}$ 2. Any nontrivial integral solution of (7) is proportional to a solution given by

$$
\begin{aligned}
x_{i} & =\pi_{2}(\alpha, \beta) \alpha_{i}, \quad i \neq p, \\
y_{i} & =\pi_{2}(\alpha, \beta) \beta_{i}, \quad i \neq p, \\
x_{p} & =d P_{p}(\beta)\left(a_{p} P_{p}(\alpha)-b_{p} P_{p}(\beta)\right), \\
y_{p} & =c P_{p}(\alpha)\left(a_{p} P_{p}(\alpha)-b_{p} P_{p}(\beta)\right) .
\end{aligned}
$$

Proof. Since the solution is nontrivial there is an integer $p$, $1 \leqq p \leqq n$, such that $a_{p} P(x) / x_{p} \neq b_{p} P(y) / y_{p}$. If for $i \neq p$ we set

$$
\begin{aligned}
& x_{i}=\pi_{2}(\alpha, \beta) \alpha_{i}, \\
& y_{i}=\pi_{2}(\alpha, \beta) \beta_{i},
\end{aligned}
$$

then (7) becomes

$$
\begin{gathered}
\pi_{2}^{n-2}(\alpha, \beta) B(\alpha) x_{p}-\pi_{2}^{n-2}(\alpha, \beta) C(\beta) y_{p}=\pi_{2}^{n-1}(\alpha, \beta)\left(b_{p} P_{p}(\beta)-a_{p} P_{p}(\alpha)\right), \\
c \pi_{2}^{n-1}(\alpha, \beta) P_{p}(\alpha) x_{p}-d \pi_{2}^{n-1}(\alpha, \beta) P_{p}(\beta) y_{p}=0 .
\end{gathered}
$$

The solution of this system is

$$
\begin{aligned}
& x_{p}=d P_{p}(\beta)\left(a_{p} P_{p}(\alpha)-b_{p} P_{p}(\beta)\right), \\
& y_{p}=c P_{p}(\alpha)\left(a_{p} P_{p}(\alpha)-b_{p} P_{p}(\beta)\right) .
\end{aligned}
$$

It follows from (9) and (10) that (8) is a solution of (7).

Suppose now that $x_{i}=\lambda_{i}, y_{i}=\mu_{i}$ is a nontrivial integral solution of (7). Then $\lambda_{p} \beta(\lambda)+a_{p} P_{p}(\lambda)=\mu_{p} C(\mu)+b_{p} P_{p}(\mu), c P(\lambda)=d P(\mu)$, and $a_{p} P(\lambda) / \lambda_{p} \neq b_{p} P(\mu) / \mu_{p}$. If in (8) we choose $\alpha_{i}=\lambda_{i}, \beta_{i}=\mu_{i}$ we obtain

$$
\begin{array}{ll}
x_{i}=\pi_{2}(\lambda, \mu) \lambda_{i}, & (i=1, \cdots, n), \\
y_{i}=\pi_{2}(\lambda, \mu) \mu_{i}, & (i=1, \cdots, n),
\end{array}
$$

which is proportional to the solution $x_{i}=\lambda_{i}, y_{i}=\mu_{i}$ since $\pi_{2}(\lambda, \mu)$ is integral and

$$
\pi_{2}(\lambda, \mu)=\frac{c P(\lambda)}{\lambda_{p} \mu_{p}}\left[\frac{a_{p} P(\lambda)}{\lambda_{p}}-\frac{b_{p} P(\mu)}{\mu_{p}}\right] \neq 0 .
$$

1 This theorem also solves the problems of Heron and Planude. 
The method of the two preceding theorems may be used to obtain solutions of the system

$$
\begin{gathered}
\sum_{i=1}^{n-1} \sum_{j=i+1}^{n}\left[\frac{a_{i j} x_{i}}{x_{j}}-\frac{b_{i j} y_{i}}{y_{j}}\right]=0, \\
c P(x)=d P(y),
\end{gathered}
$$

where $c, d, P(\alpha)$ are defined above and the $a_{i j}, b_{i j}$ are integers. We define

$$
\begin{aligned}
P_{i j}(\alpha) & =\frac{P(\alpha)}{\alpha_{i} \alpha_{j}} \\
D(\alpha, \beta) & =\sum_{j=2}^{n} a_{1 j} P_{1 j}(\alpha) P_{1}(\beta), \\
E(\alpha, \beta) & =\sum_{j=2}^{n} b_{1 j} P_{1}(\alpha) P_{1 j}(\beta), \\
F(\alpha, \beta) & =\sum_{i=2}^{n-1} \sum_{j=i+1}^{n}\left(a_{i j} \alpha_{i} P_{1 j}(\alpha) P_{1}(\beta)-b_{i j} \beta_{i} P_{1}(\alpha) P_{1 j}(\beta)\right), \\
\pi_{3}(\alpha, \beta) & =c P_{1}(\alpha) E(\alpha, \beta)-d P_{1}(\beta) D(\alpha, \beta), \\
G(\alpha, \beta) & =\sum_{i=1}^{n-1} a_{i n} \alpha_{i} P_{n}(\alpha) P_{n}(\beta), \\
H(\alpha, \beta) & =\sum_{i=1}^{n-1} b_{i n} \beta_{i} P_{n}(\alpha) P_{n}(\beta), \\
I(\alpha, \beta) & =\sum_{j=2}^{n-1} \sum_{i=1}^{j-1}\left(a_{i j} \alpha_{i} P_{n j}(\alpha) P_{n}(\beta)-b_{i j} \beta_{i} P_{n}(\alpha) P_{n j}(\beta)\right), \\
\pi_{4}(\alpha, \beta) & =c d P_{n}(\alpha) P_{n}(\beta) I(\alpha, \beta) .
\end{aligned}
$$

THEOREM 3. Any nonzero integral solution of (11) which does not satisfy

$$
\sum_{j=2}^{n}\left[\frac{b_{1 j} \mu_{1}}{\mu_{j}}-\frac{a_{1 j} \lambda_{1}}{\lambda_{j}}\right]=0,
$$

is proportional to a solution given by

$$
\begin{aligned}
& x_{i}=\pi_{3}(\alpha, \beta) \alpha_{i}, \quad i \neq 1, \\
& y_{i}=\pi_{3}(\alpha, \beta) \beta_{i}, \quad i \neq 1, \\
& x_{1}=d P_{1}(\beta) F(\alpha, \beta), \\
& y_{1}=c P_{1}(\alpha) F(\alpha, \beta),
\end{aligned}
$$

and any non-zero integral solution which does not satisfy

$$
\sum_{i=1}^{n-1}\left[\frac{b_{i n} \mu_{i}}{\mu_{n}}-\frac{a_{i n} \lambda_{i}}{\lambda_{n}}\right]=0,
$$


is proportional to a solution given by

$$
\begin{aligned}
x_{i} & =\pi_{4}(\alpha, \beta) \alpha_{i}, \quad i \neq n, \\
y_{i} & =\pi_{4}(\alpha, \beta) \beta_{i}, \quad i \neq n, \\
x_{n} & =d P_{n}(\beta)\left(d P_{n}(\beta) H(\alpha, \beta)-c P_{n}(\alpha) G(\alpha, \beta)\right), \\
y_{n} & =c P_{n}(\alpha)\left(d P_{n}(\beta) H(\alpha, \beta)-c P_{n}(\alpha) G(\alpha, \beta)\right) .
\end{aligned}
$$

Proof. If we multiply the first of the equations in (11) by $P_{1}(x) P_{1}(y)$ and for $i \neq 1$ set

$$
\begin{aligned}
& x_{i}=\pi_{3}(\alpha, \beta) \alpha_{i}, \\
& y_{i}=\pi_{3}(\alpha, \beta) \beta_{i},
\end{aligned}
$$

the system becomes

$$
\begin{aligned}
\pi_{3}^{2 n-3}(\alpha, \beta) D(\alpha, \beta) x_{1}-\pi_{3}^{2 n-3}(\alpha, \beta) E(\alpha, \beta) y_{1} & =-\pi_{3}^{2 n-2}(\alpha, \beta) F(\alpha, \beta) \\
c \pi_{3}^{n-1}(\alpha, \beta) P_{1}(\alpha) x_{1}-d \pi_{3}^{n-1}(\alpha, \beta) P_{1}(\beta) y_{1} & =0
\end{aligned}
$$

which has as solution

$$
\begin{aligned}
& x_{1}=d P_{1}(\beta) F(\alpha, \beta), \\
& y_{1}=c P_{1}(\alpha) F(\alpha, \beta) .
\end{aligned}
$$

From (16) and (17) it follows that (13) is a solution of (11).

Suppose now that $x_{i}=\lambda_{i}, y_{i}=\mu_{i}$ is any nonzero integral solution of (11) which does not satisfy (12). If we choose $\alpha_{i}=\lambda_{i}, \beta_{i}=\mu_{i}$ then (13) becomes

$$
\begin{array}{ll}
x_{i}=\pi_{3}(\lambda, \mu) \lambda_{i}, & (i=1, \cdots, n), \\
y_{i}=\pi_{3}(\lambda, \mu) \mu_{i}, & (i=1, \cdots, n),
\end{array}
$$

which is proportional to the solution $x_{i}=\lambda_{i}, y_{i}=\mu_{i}$ since $\pi_{3}(\lambda, \mu)$ is integral and

$$
\pi_{3}(\lambda, \mu)=\frac{c P(\lambda) P_{1}(\lambda) P_{1}(\mu)}{\lambda_{1} \mu_{1}} \sum_{j=2}^{n}\left[\frac{b_{1 j} \mu_{1}}{\mu_{j}}-\frac{a_{1 j} \lambda_{1}}{\lambda_{j}}\right] \neq 0 .
$$

We may now write (11) as

$$
\begin{gathered}
\sum_{j=2}^{n} \sum_{j=1}^{j-1}\left[\frac{a_{i j} x_{i}}{x_{j}}-\frac{b_{i j} y_{i}}{y_{j}}\right]=0, \\
c P(x)=d P(y) .
\end{gathered}
$$

If we multiply the first equation in (18) by $P_{n}(x) P_{n}(y)$ and for $i \neq n$ set

$$
\begin{aligned}
& x_{i}=\pi_{4}(\alpha, \beta) \alpha_{i}, \\
& y_{i}=\pi_{4}(\alpha, \beta) \beta_{i},
\end{aligned}
$$


the system becomes

$$
\begin{aligned}
& \frac{1}{x_{n}} \pi_{4}^{2 n-1}(\alpha, \beta) G(\alpha, \beta)-\frac{1}{y_{n}} \pi_{4}^{2 n-1}(\alpha, \beta) H(\alpha, \beta)=-\pi_{4}^{2 n-2}(\alpha, \beta) I(\alpha, \beta), \\
& \frac{1}{x_{n}} \pi_{4}^{n-1}(\alpha, \beta) d P_{n}(\beta)-\frac{1}{y_{n}} \pi_{4}^{n-1}(\alpha, \beta) c P_{n}(\alpha)=0
\end{aligned}
$$

which has solution

$$
\begin{aligned}
& x_{n}=d P_{n}(\beta)\left(d P_{n}(\beta) H(\alpha, \beta)-c P_{n}(\alpha) G(\alpha, \beta)\right), \\
& y_{n}=c P_{n}(\alpha)\left(d P_{n}(\beta) H(\alpha, \beta)-c P_{n}(\alpha) G(\alpha, \beta)\right) .
\end{aligned}
$$

It follows from (19) and (20) that (15) is a solution of (18) and hence of (11).

Suppose now that $x_{i}=\lambda_{i}, y_{i}=\mu_{i}$ is any nonzero integral solution of (18) which does not satisfy (14). If in (15) we choose $\alpha_{i}=\lambda_{i}$, $\beta_{i}=\mu_{i}$ we get

$$
\begin{array}{ll}
x_{i}=\pi_{4}(\lambda, \mu) \lambda_{i}, & (i=1, \cdots, n), \\
y_{i}=\pi_{4}(\lambda, \mu) \mu_{i}, & (i=1, \cdots, n),
\end{array}
$$

which is proportional to the solution $x_{i}=\lambda_{i}, y_{i}=\mu_{i}$ since $\pi_{4}(\lambda, \mu)$ is integral and

$$
\pi_{4}(\lambda, \mu)=c d P_{n}^{2}(\lambda) P_{n}^{2}(\mu) \sum_{i=1}^{n-1}\left[\frac{b_{i n} \mu_{i}}{\mu_{n}}-\frac{a_{i n} \lambda_{i}}{\lambda_{n}}\right] \neq 0
$$

The following example shows that not all systems of type (11) can be solved by the method of this paper. The system

$$
\begin{gathered}
\sum_{i=1}^{3} \sum_{j=i+1}^{4}\left[\frac{a_{i j} x_{i}}{x_{j}}-\frac{b_{i j} y_{i}}{y_{j}}\right]=0, \\
c \prod_{i=1}^{4} x_{i}=d \prod_{i=1}^{4} y_{i},
\end{gathered}
$$

where $a_{12}=3, a_{13}=-2, a_{14}=3, a_{23}=4, a_{24}=4, a_{34}=3, b_{12}=6, b_{13}=-2$, $b_{14}=3, b_{23}=8, b_{24}=2, b_{34}=3, c=2, d=1$, has the solution

$$
x_{1}=2, x_{2}=3, x_{3}=-4, x_{4}=-2, y_{1}=4, y_{2}=-3, y_{3}=-4, y_{4}=2 \text {, }
$$

which also satisfies

$$
\sum_{j=2}^{4}\left[\frac{a_{1,} x_{1}}{x_{j}}-\frac{b_{1,} y_{1}}{y_{j}}\right]=0
$$

and

$$
\sum_{i=1}^{3}\left[\frac{a_{i 4} x_{i}}{x_{4}}-\frac{b_{i 4} y_{i}}{y_{4}}\right]=0 .
$$




\section{BIBLIOGRAPHY}

1. U. Bini, L'Intermediaire des Mathematiciens 16 (1909), 42-43.

2. M. Buquet, Sphinx 8 (1938), 207.

3. L. E. Dickson, History of the Theory of Numbers, vol. 2, Reprinted, Steckert, New York, 1934.

4. - On certain Diophantine equations, The Messenger of Mathematics 39 (1910), 86-87.

5. —_- Rational Edged Cuboids with Equal Volumes and Equal Surfaces, Amer. Math. Monthly 16 (1909), 107-114.

6. A. Gloden, Sur le Systeme Diophantien $x+y+z=u+v+w, x y z=u v w$, Boletin Matematico 12 (1939), 205-209.

7. A. Moessner, Numerische Identitaeten, Boletin Matematico 7 (1934), 68.

8. ______, Zahleneigentuemlichkeiten, Boletin Matematico 10 (1937), 34.

Received November 16, 1966. This paper was written with the aid of a Roy Henry Cullen Grant for Research in Mathematics.

UNIVERSITY OF HOUSTON 



\section{PACIFIC JOURNAL OF MATHEMATICS}

\section{H. ROYDEN}

Stanford University

Stanford, California

\author{
J. P. JANS \\ University of Washington \\ Seattle, Washington 98105
}

\section{EDITORS}

\author{
J. DugundJI \\ Department of Mathematics \\ Rice University \\ Houston, Texas 77001 \\ Richard ARENS \\ University of California \\ Los Angeles, California 90024
}

\section{ASSOCIATE EDITORS}
E. F. BECKENBACH
B. H. NeumanN
F. WOLF
K. YOSIDA

\section{SUPPORTING INSTITUTIONS}

\author{
UNIVERSITY OF BRITISH COLUMBIA \\ CALIFORNIA INSTITUTE OF TECHNOLOGY \\ UNIVERSITY OF CALIFORNIA \\ MONTANA STATE UNIVERSITY \\ UNIVERSITY OF NEVADA \\ NEW MEXICO STATE UNIVERSITY \\ OREGON STATE UNIVERSITY \\ UNIVERSITY OF OREGON \\ OSAKA UNIVERSITY \\ UNIVERSITY OF SOUTHERN CALIFORNIA
}

\author{
STANFORD UNIVERSITY \\ UNIVERSITY OF TOKYO \\ UNIVERSITY OF UTAH \\ WASHINGTON STATE UNIVERSITY \\ UNIVERSITY OF WASHINGTON \\ AMERICAN MATHEMATICAL SOCIETY \\ CHEVRON RESEARCH CORPORATION \\ TRW SYSTEMS \\ NAVAL ORDNANCE TEST STATION
}

Mathematical papers intended for publication in the Pacific Journal of Mathematics should be typewritten (double spaced). The first paragraph or two must be capable of being used separately as a synopsis of the entire paper. It should not contain references to the bibliography. Manuscripts may be sent to any one of the four editors. All other communications to the editors should be addressed to the managing editor, Richard Arens at the University of California, Los Angeles, California 90024.

50 reprints per author of each article are furnished free of charge; additional copies may be obtained at cost in multiples of 50 .

The Pacific Journal of Mathematics is published monthly. Effective with Volume 16 the price per volume (3 numbers) is $\$ 8.00$; single issues, $\$ 3.00$. Special price for current issues to individual faculty members of supporting institutions and to individual members of the American Mathematical Society: $\$ 4.00$ per volume; single issues $\$ 1.50$. Back numbers are available.

Subscriptions, orders for back numbers, and changes of address should be sent to Pacific Journal of Mathematics, 103 Highland Boulevard, Berkeley 8, California.

Printed at Kokusai Bunken Insatsusha (International Academic Printing Co., Ltd.), 7-17, Fujimi 2-chome, Chiyoda-ku, Tokyo, Japan.

PUBLISHED BY PACIFIC JOURNAL OF MATHEMATICS, A NON-PROFIT CORPORATION

The Supporting Institutions listed above contribute to the cost of publication of this Journal, but they are not owners or publishers and have no responsibility for its content or policies. 


\section{Pacific Journal of Mathematics}

A. A. Aucoin, Diophantine systems ............................. 419

Charles Ballantine, Products of positive definite matrices. I ............... 427

David Wilmot Barnette, A necessary condition for d-polyhedrality ............ 435

James Clark Beidleman and Tae Kun Seo, Generalized Frattini subgroups of finite groups ......................................... 441

Carlos Jorge Do Rego Borges, A study of multivalued functions ............. 451

William Edwin Clark, Algebras of global dimension one with a finite ideal

lattice ...............................................

Richard Brian Darst, On a theorem of Nikodym with applications to weak convergence and von Neumann algebras .........................

George Wesley Day, Superatomic Boolean algebras .....................

Lawrence Fearnley, Characterization of the continuous images of all

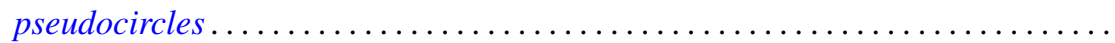

Neil Robert Gray, Unstable points in the hyperspace of connected subsets....... 515

Franklin Haimo, Polynomials in central endomorphisms .................. 521

John Sollion Hsia, Integral equivalence of vectors over local modular lattices . . . . 527

Jim Humphreys, Existence of Levi factors in certain algebraic groups .......... 543

E. Christopher Lance, Automorphisms of postliminal $C^{*}$-algebras ............ 547

Sibe Mardesic, Images of ordered compacta are locally peripherally metric . . . . 557

Albert W. Marshall, David William Walkup and Roger Jean-Baptiste Robert Wets,

Order-preserving functions: Applications to majorization and order

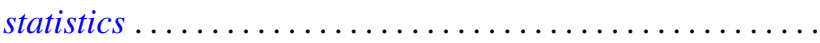

Wellington Ham Ow, An extremal length criterion for the parabolicity of

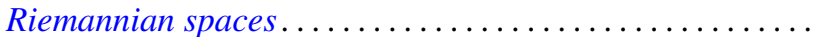

585

Wellington Ham Ow, Criteria for zero capacity of ideal boundary components of

Riemannian spaces...................................... 591

J. H. Reed, Inverse limits of indecomposable continua .................. 597

Joseph Gail Stampfli, Minimal range theorems for operators with thin spectra . . . 601

Roy Westwick, Transformations on tensor spaces..................... 613

Howard Henry Wicke, The regular open continuous images of complete metric

spaces ........................................... 621

Abraham Zaks, A note on semi-primary hereditary rings .............. 627

Thomas William Hungerford, Correction to: "A description of $\operatorname{Mult}_{i}\left(A^{1}, \cdots, A^{n}\right)$

by generators and relations" ............................. 629

Uppuluri V. Ramamohana Rao, Correction to: "On a stronger version of Wallis' formula".............................................. 629

Takesi Isiwata, Correction: "Mappings and spaces" ................... 630

Henry B. Mann, Josephine Mitchell and Lowell Schoenfeld, Correction to:

"Properties of differential forms in $n$ real variables" .... . .

James Calvert, Correction to: "An integral inequality with applications to the

Dirichlet problem"............................. 